\section{Pleomorphic adenoma of the soft palate}

Received: 5 November 2009 / Accepted: 25 January 2010

(C) Association of Oral and Maxillofacial Surgeons of India 2009

\author{
Sourav Singh ${ }^{1} \otimes \cdot$ Shivamurthy $\mathbf{D M}^{2}$. \\ Rohit Agarwal ${ }^{3}$ \\ ${ }^{1}$ Professor \\ ${ }^{2}$ Professor and Head \\ ${ }^{3}$ PG Student
}

Dept. of Oral Medicine and Maxillofacial Surgery, Darshan Dental College and Hospital, Udaipur

Address for correspondence:

Sourav Singh

Professor

Dept. of Oral and Maxillofacial Surgery

Darshan Dental College and Hospital

Udaipur, India

E-mail: udaipurdentalclinic@rediffmail.com

Keywords Pleomorphic adenoma $\cdot$ Minor salivary gland tumours

\section{Introduction}

Pleomorphic adenoma is the commonest benign tumour to arise in the minor salivary glands. However, majority of minor salivary gland tumours are of the malignant variety.

A case of a large pleomorphic adenoma of the minor salivary glands arising de novo in the soft palate is described.

\section{Case report}

A 40-year-old male presented with a gradually increasing painless swelling on the palate associated with dysphagia and change in speech.

On examination there was smooth bulge on the left side of the soft palate crossing the midline (Fig. 1). The swelling was bulging towards the oropharynx and pushing the uvula to the contralateral side. The swelling was firm and smooth with an intact healthy overlying mucosa. There was no significant lymph node enlargement in the neck.

MRI scan revealed a peripherally enhancing, large pear shaped tumour measuring $34 \mathrm{~mm} \times 34 \mathrm{~mm} \times 26 \mathrm{~mm}$ on the left side of soft palate, crossing the midline, extending into the left oropharynx and compressing upon the left parapharyngeal space (Fig. 2).

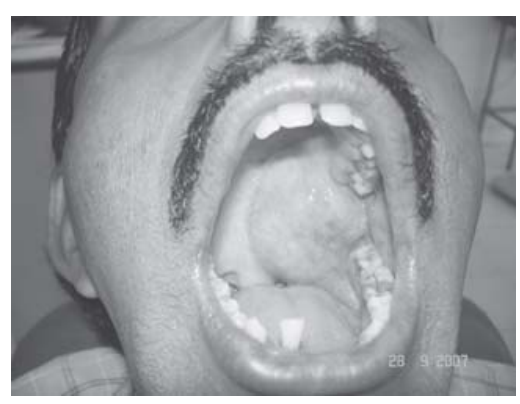

Fig. 1 Intra-oral appearance of the tumour

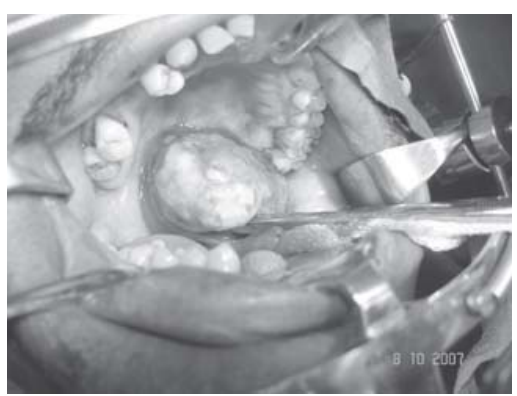

Fig. 3 Tumour being excised out

FNAC of the lesion was performed and the smear revealed moderate cellularity comprising of benign mononuclear cells arranged in clumps and forming acini at places. The background showed eosinophilic material and RBCs. No atypical cells were seen. The findings were consistent with a benign glandular lesion.

The patient was operated under general anaesthesia and nasoendotracheal intubation

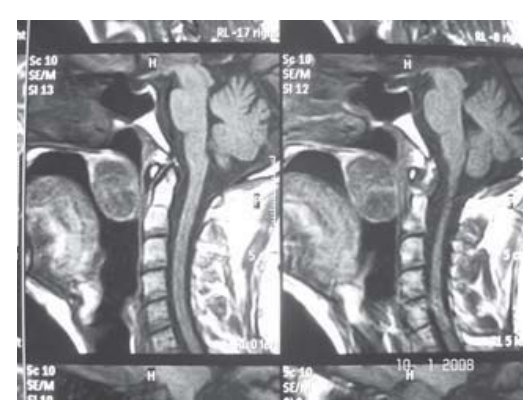

Fig. 2 MRI scan of the tumour

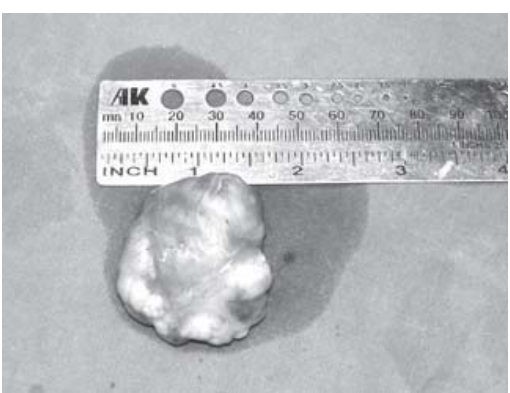

Fig. 4 Excised tumour

through the opposite nostril. A longitudinal incision was placed over the crest of the swelling. The tumour was released from its surrounding attachments by a blunt dissection along the cleavage plane (Fig. 3).

The tumour was encapsulated with a glistening, smooth, faintly lobulated surface measuring $35 \mathrm{~mm} \times 35 \mathrm{~mm} \times 25 \mathrm{~mm}$ in size (Fig. 4) 


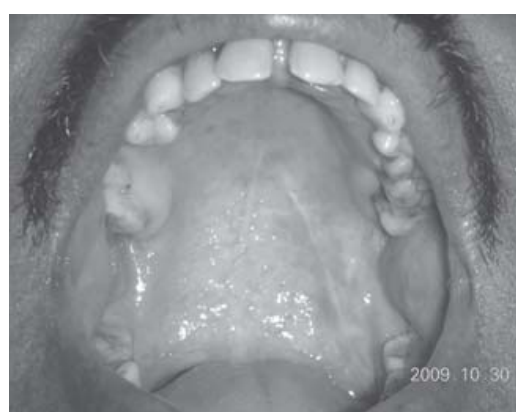

Fig. 5 Tumour site 2 year postoperative

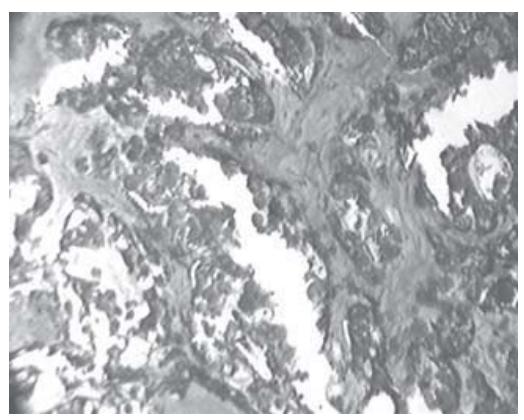

Fig. 6 Photomicrograph of the tumour specimen

Postoperatively the patient was prescribed IV antibiotics (Ceftriaxone 1 gm BD) and analgesics (IM Diclofenac $75 \mathrm{mg}$ BD) for 5 days. The healing was uneventful. The patient has been disease free for the past 2 year period of followup (Fig. 5).
Histopathological examination revealed a neoplasm with a fibrous connective tissue capsule, nests of polygonal shaped epithelial cells, myoepithelial cells with a plasmacytoid appearance and areas of myxoid, osteoid and hyalinized eosinophilic connective tissue. The overall features were suggestive of pleomorphic adenoma (Fig. 6).

\section{Discussion}

Tumours arising in the minor salivary glands account for upto $22 \%$ of all salivary gland neoplasm [1,4]. Majority are malignant with only $18 \%$ being benign. The commonest site of occurrence of pleomorphic adenomas of minor salivary glands is the palate followed by lip, buccal mucosa, floor of the mouth, tongue, tonsil, pharynx, retromolar area and nasal cavity $[1,3]$.

MRI is an essential tool for the imaging of soft palate tumours as it aids in determining the extent and nature of the lesion, local spread and also the neoplastic status [6].

The tumours involving the soft palate and the adjoining areas especially the parapharyngeal space are also known to arise as an extension from the deep lobe of the parotid gland. Such tumours have to be distinguished from those arising de novo. This can be differentiated by a distinct fine lucent line representing the compressed layer of fibro adipose tissue between the tumour and the deep lobe of parotid when seen on a MRI scan [5].

\section{References}

1. Spiro SH (1986) Salivary Neoplasm: overview of a 35 years experience with 2807 patients. Head Neck Surg 8(3): 177-184

2. Waldron CA, el-Mofty SK, Gnepp DR (1988) Tumours of the intra-oral salivary glands: A demographic and histologic study of 426 cases. Oral Surg Oral Med Oral Pathol 66(3): 323-333

3. Cohen MA (1986) Pleomorphic adenoma of the cheek. Int J Oral Maxillofac Surg 15(6): 777-779

4. Varghese BT, Sebastian P, Abraham EK, Mathews A (2003) Pleomorphic adenoma of minor salivary gland in the parapharyngeal space. World J Surg Oncol 1(1): 2

5. Heeneman H (1987) Parapharyngeal space tumours. Kerr AG, editor. Scott Brown's Otolaryngology. Butterworth \& Co, 380-391

6. Som PM, Bergen RT (1991) Head and neck imaging 2nd edn. St Louis, Mosby 277-348 